\title{
Carotid body tumor excision via double mandibular osteotomy: highligting the role of the head and neck surgeon in the multidisciplinary management
} \author{
Antoniades ${ }^{1}$ and Konstantinos Vahtsevanos ${ }^{1}$ \\ ${ }^{1}$ Department of Oral and Maxillofacial Surgery, G. Papanikolaou General Hospital, Thessaloniki, Greece \\ ${ }^{2}$ Department of Oncology, Geneva University Hospitals, Geneva, Switzerland \\ ${ }^{3}$ Department of Vascular Surgery, G. Papanikolaou General Hospital, Thessaloniki, Greece \\ ${ }^{4}$ Department of Radiology, G. Papanikolaou General Hospital, Thessaloniki, Greece \\ ${ }^{5}$ Department of Histopathology, G. Papanikolaou General Hospital, Thessaloniki, Greece
}

Konstantinos Paraskevopoulos ${ }^{*}$, Anna Patrikidou ${ }^{2}$, Angelos Megalopoulos ${ }^{3}$, Panagiotis Palladas ${ }^{4}$, Angeliki Cheva ${ }^{5}$ Konstantinos

\begin{abstract}
Background: Carotid body is a small mass of tissue in the carotid sinus containing chemoreceptors that monitor levels of oxygen, carbon dioxide, and hydrogen ions in the blood. Carotid body tumors (CBTs) are rare and found at carotid bifurcation. They are painless neck masses, which expand slowly and they could press the neighboring neurovascular tissues. Because of their proximity to cranial nerves, neurological symptoms could present. The tumors are mostly benign. They can present at any age and appear at the same frequency in either sex.
\end{abstract}

Subjects and methods: We report a case series of CBTs managed at the G. Papanikolaou General Hospital, Thessaloniki, Greece between 2002 and 2016 , aiming to highlight the multidisciplinary management of CBTs and highlight the role of head and neck surgeon.

Results: Eight cases of CBT resection are reported. All tumors were excised by vascular and maxillofacial surgeons after preoperative embolization of the feeding vessels. Double mandibular osteotomy (DMO) was the surgical approach of choice, as it enables ample access to the parapharyngeal space and facilitates safe excision. All patients are still in follow up. There were no postoperative cerebral strokes or mortality, but other post-operative complications occurred, notably cranial nerve palsies. No revealed recurrence of CBT was observed.

Conclusion: A collaborative, multidisciplinary approach is essential in the management of these highly vascular tumours with a reported high rate of neurological complications.

\section{Introduction}

Carotid body tumors (CBTs), belonging to the extra-adrenal paragangliomas, arise from chomaffin-negative chemoreceptor cells found at the common carotid artery bifurcation. First described by Von Haller in 1743 [1], they are extra-adrenal paragangliomas are neoplasms of the paraganglia located within the paravertebral sympathetic and parasympathetic chains. Head and neck paragangliomas account for up to $70 \%$ of extra-adrenal paragangliomas, the most common site (up to $50 \%$ ) being the carotid body $[2,3]$. Only in $1-3 \%$ head of paraganglioma cases is secretion of hormones such as catecholamines abundant enough to be clinically significant. Malignancy is rate, reported in up to $6 \%$ $[4,5]$. Familial incidence is reported to be approximately $10 \%$, although there have been reported series of up to $30 \%$, usually with bilateral involvement [6]. Several genes have been identified and are thought to contribute to the development of pheochromocytoma/paraganglioma (RET, VHL, NF1 and SDH subunits SDHB, SDHC, and SDHD). SDHD and SDHB mutations account for a significant percentage of head and neck paragangliomas [3]. Paragangliomas may also occur in the context of Von Hippel Lindau syndrome, neurofibromatosis 1 or multiple endocrine neoplasia (MEN) syndromes type $2 \mathrm{~A}$ or $2 \mathrm{~B}$. Other genes related to familiar paraganglioma are SDHAF2, TMEM127 and MAX.
CBTs are painless neck masses with typical location, vessel displacement and specific blood supply. They usually expand slowly and they could press the neighboring neurovascular tissues [7]. CBTs can present at any age and appear at the same frequency in either sex [8]. Functional, cathecholamine-secreting carotid body tumors are exceedingly rare $[9,10]$. The tumors are mostly benign and the incidence of malignancy is $3 \%$ to $4 \%[11,12]$, so they should be surgically excised as early as possible to avoid the local spread, but also to minimize neurological complication owing to large tumour size and anatomic vicinity with cranial nerves.

It is crucial to make a correct preoperative diagnosis. Differential diagnosis includes a thyroid nodule, lymphadenopathy, brachial cyst,

Correspondence to: Konstantinos Paraskevopoulos, Department of Oral and Maxillofacial Surgery, G. Papanikolaou General Hospital, Eksoxi, 57010 Thessaloniki, Greece, Tel: +302313307275, Fax: 00302313307074; E-mail: kostparas@yahoo.gr

Key words: paragangliomas, carotid body tumor, double mandibular osteotomy, embolization

Received: July 07, 2017; Accepted: July 26, 2017; Published: August 01, 2017 

management

middle ear adenoma, meningioma and schwannoma [3,4]. In general, radiographic studies are pathognomonic, so fine needle biopsy is not indicated [12]. Ultrasound may be the first imaging procedure to determine the nature of a neck mass. Angiography can provide invaluable information on the lesion vascularisation, while CT and MRI offer more accurate locoregional assessment [13].

\section{Subjects and methods}

We performed a retrospective analysis of patients managed for a carotid body tumor at the G. Papanikolaou General Hospital, Thessaloniki, Greece between 2002 and 2016, aiming to highlight the multidisciplinary management of CBTs and highlight the role of head and neck surgeon. Data collection was based on electronic and paper records. Informed consent for surgical procedures was obtained from all the patients.

\section{Results}

Between 2002 and 2016, eight patients with CBT were managed at G. Papanikolaou General Hospital (1 male, and 7 female patients, median age: 50 years, range: 35-66 years) (Table 1). All patients presented with a slow-growing neck swelling, without any symptoms of cranial nerve involvement. No relevant family history was reported in any of these cases. Clinical examination did not identify signs or symptoms indicative of genetic syndromes such as Von Hippel-Lindau, neurofibromatosis 1 or MEN 2A or 2B. Preoperative imaging evaluation did not identify other lesions, notably no lymph node involvement. Baseline endocrinology and cardiovascular assessment was normal, confirming an isolated non-secreting carotid body paraganglioma in all cases.

Preoperative imaging by CT scan of the head and neck and orthopantomogram was used to assess Shamblin type (Table 1) and mandibular anatomy and position of the mental foramen so as to optimise surgical access. All patients underwent digital substraction angiography, typically showing intense tumor blush (Figure 1), followed by pre-operative particle embolization of the feeding vessels. The efficacy of embolization was assessed via comparison of pre- and postembolization angiographies (Figure 1). Surgery of CBTs was performed at a 24-hour interval post-embolization and involved a collaborative effort by a vascular and maxillofacial surgeons team. Surgical access to the parapharyngeal space was performed by maxillofacial surgeons, followed by resection of CBTs by vascular surgeons. In all of these cases, double osteotomy of the mandible (DMO) was necessary in order to access the tumor (Figure 2). This surgical technique consists of two mandibular osteotomies, as previously described [14,15]. The first vertical subsigmoid one is positioned posterior to the lingula in order to avoid injury of the inferior alveolar nerve. The second osteotomy is performed in front of the mental foramen protecting the mental nerve (Figure 3). After the excision of the tumor, the mandible was reconstructed via mini-plate osteosynthesis.

Histological examination revealed highly vascular tumors composed of dual cell population arranged in clusters (Zellballen pattern). The chief cells (type I) were epithelioid, small- medium size, uniform cells, with granular, pink to clear cytoplasm. They were more numerous than type II cells and expressed CD56, synaptophysin and chromogranin but not cytokeratin. The sustentacular cells (type II) located at the periphery of the Zellballen pattern expessed S-100 protein and GFAP (Glial fibrillary acidic protein) (Figure 4). No malignant component was identified in any specimen.

There were no postoperative strokes or mortality. All patients are still in follow up, without recurrence of CBT. Post-operative complications were observed in five cases. Transient marginal mandibular nerve paresis was observed in one patient, resolving within the next four months after the surgery. A second patient suffered transient hypoglossal nerve paresis and a third one suffered dysphonia due to left vocal fold paresis, also resolving. A fourth patient had inferior alveolar and lingual nerve paresis and lingual fibrillation. After a few months follow-up, the inferior alveolar nerve paresis had 3 completely resolved, with persistence of the lingual nerve paresis. Another patient suffered marginal mandibular and hypoglossal nerve paresis with dysphonia and dysphagia. In the next seven months, we observed improvement of these symptoms but accessory nerve paresis appeared. Two years later, the patient showed aggravation of her neurological condition with palsy of the VII, VIII, IX, X, XI, XII cranial nerves (Table 1).

\section{Discussion}

Carotid body is a small mass of tissue in the carotid sinus containing chemoreceptors that monitor levels of oxygen, carbon dioxide, and hydrogen ions in the blood [16]. In 1971, Shamblin categorized CBTs in three types; Shamblin I: small tumors not encasing the vessels, Shamblin II: tumors partially encasing the vessels, Shamblin III: tumors completely encasing the vessels [17]. CBTs expand slowly and are usually painless. The proximity of CBTs to cranial nerves, especially X, XI, XII causes neurological symptoms [18], notably in tumors of higher Shamblin group. The risk of intraoperative cranial nerves injuries depends on the location of CBTs, and it is higher in large tumors [19,20], rendering the assessment of preoperative status of cranial nerves crucial. The rates of reported cranial nerve injury are high, with overall rates of $11 \%$ to $49 \%$ $[11,21]$ and permanent nerve deficit rates of $11 \%-20 \%$ [6].

Table 1. Patient cohort demographics, tumour description, post-operative functional outcome.

\begin{tabular}{|c|c|c|c|c|c|c|}
\hline Patient No & Sex & Age & CBT Side & Size & Shamblin Type & Complications \\
\hline 1 & Female & 44 & Left & $5 \times 3 \times 3 \mathrm{~cm}$ & III & $\begin{array}{l}\text { Transient marginal mandibular nerve paresis. } \\
\text { Hypoglossal nerve paresis (improved but not entirely resolved). } \\
\text { Late-onset accessory nerve paresis. } \\
\text { Very late-onset palsy of the VII, VIII, IX, X, XI, XII cranial } \\
\text { nerves. }\end{array}$ \\
\hline 2 & Female & 46 & Left & $3.5 \times 2.5 \times 1.5 \mathrm{~cm}$ & II & Transient hypoglossal nerve paresis \\
\hline 3 & Female & 49 & Left & $4 \times 2 \times 2.5 \mathrm{~cm}$ & II & Transient left vocal fold paresis \\
\hline 4 & Female & 53 & Left & $2.7 \times 2 \times 1.6 \mathrm{~cm}$ & III & $\begin{array}{l}\text { Internal carotid rupture. } \\
\text { Transient hypoaesthesia lower alveolar nerve. } \\
\text { Fibrillation left hemi-tongue (improved but not entirely } \\
\text { resolved). }\end{array}$ \\
\hline 5 & Female & 61 & Right & $6.5 \times 5 \times 1.5 \mathrm{~cm}$ & II & None \\
\hline 6 & Female & 66 & Right & $2.8 \times 2.5 \times 2 \mathrm{~cm}$ & II & Transient paresis of right manginal mandibular nerve \\
\hline 7 & Male & 35 & Left & $2.9 \times 3.1 \times 1.8 \mathrm{~cm}$ & II & None \\
\hline 8 & Female & 59 & Right & $3 \times 1.9 \times 1.6$ & II & None \\
\hline
\end{tabular}




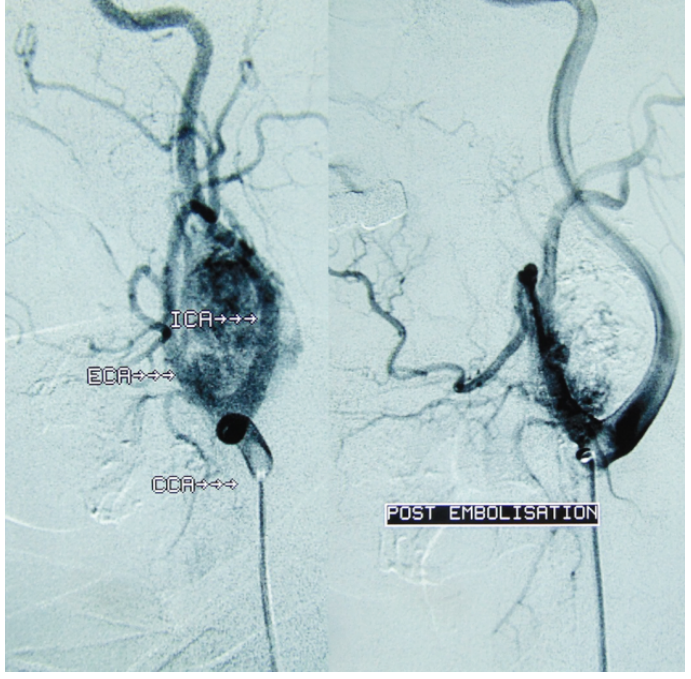

Figure 1. Digital substraction angiography, before (left) and after embolization (right)

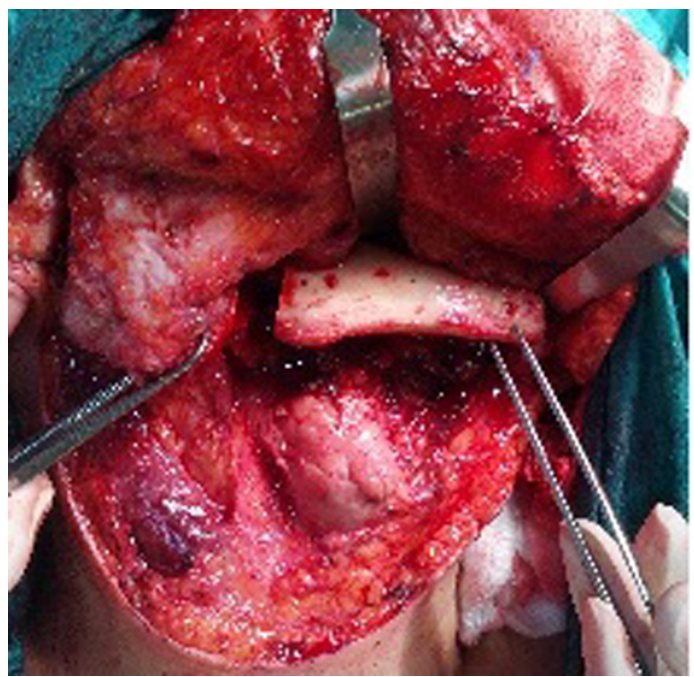

Figure 2. Double osteotomy of the mandible via transcervical approach (intra-operative picture).

Given these intricacies, a designed multidisciplinary approach optimizes management and aims to minimize peri-operative morbidity.

Preoperative embolization of the feeding vessels is a valuable intervention for these vascular tumours [22], notably helping to reduce perioperative bleeding especially in cases of large CBTs, and thus reducing operative time. It does not, however, decrease rates of cranial nerve injury [23-25].

Our approach of choice was double osteotomy of the mandible. This technique provides excellent access to the entire parapharyngeal space, in contrast to the difficulty encountered with non-DMO approaches $[26,27]$. This is necessary to enable complete removal of CBTs and vascular control, therefore obtaining radical excision and minimal functional or cosmetic effects after the surgery [14,15,26,28,29]. Indeed, even authors that advocate non-osteotomy approaches, they have opted for an osteotomy in cases of suspicion of malignant disease, hence required ample anatomical access to the parapharyngeal space. Furthermore, the modification of the technique used, initially described by our team $[14,15]$ and subsequently by others $[28,29]$, avoids the necessity for a lip-incision approach. Finally, the the subsigmoid osteotomy provides larger bony surface for application of rigid fixation, as opposed to a subcondylar osteotomy $[15,28]$.

In conclusion, our case series highlight the importance and value of multidisciplinarity in the management of CBTs, highlighting the valuable role of the head and neck surgeon in this demanding and functionally delicate anatomical region.

\section{Conflict of interest}

The authors declare that they have no conflict of interest.

\section{Ethical approval}

All procedures performed in studies involving human participants were in accordance with the ethical standards of the institutional and/ or national research committee and with the 1964 Helsinki declaration and its later amendments or comparable ethical standards.

\section{Informed consent}

Informed consent was obtained from all individual participants included in the study.

A
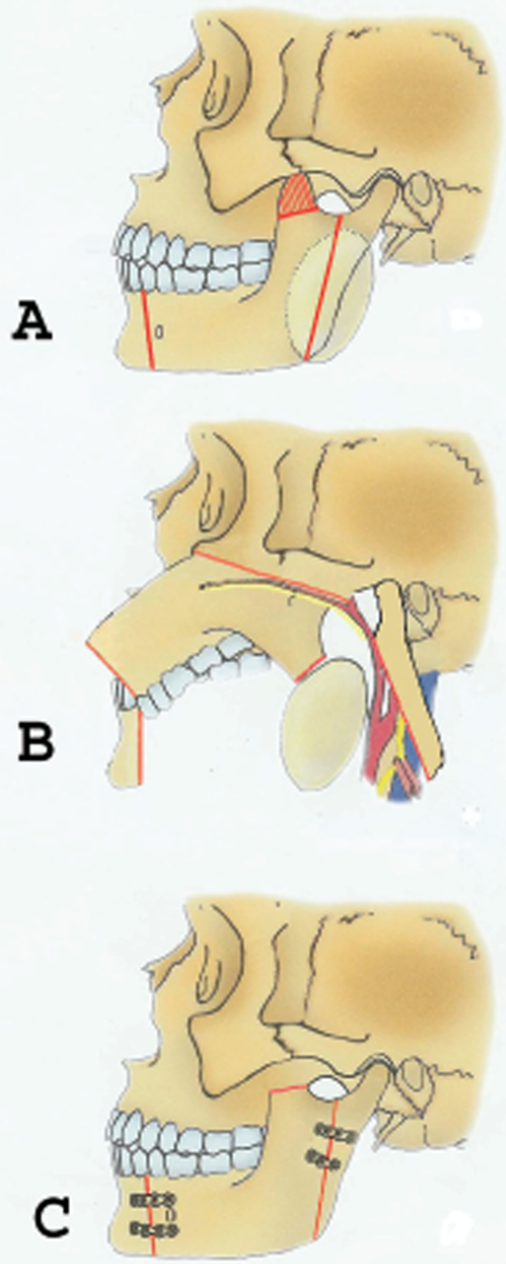

Figure 3. A. Diagram showing the design of the bone cuts for the type of double mandibular osteotomy anterior to the mental foramen combined with a vertical ramus osteotomy and coronoidectomy. B. Osteotomy segments are retracted superiorly and laterally. C. After the tumor has been removed, the osteotomized mandibular segments are reapproximated and stabilized with the adapted bone plates (Reprinted with permission from Lazaridis and Antoniades J Oral Maxillofac Surg 2008). 


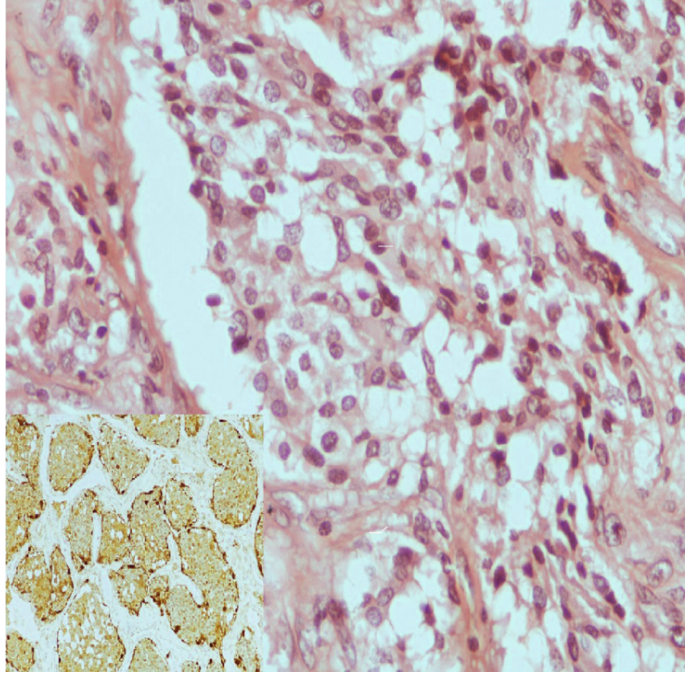

Figure 4. Immunohistochemical appearance of resected CBT: H\&E (x400), S-100 (x200, inset photo).

\section{References}

1. Milewski C (1993) Morphology and clinical aspects of paragangliomas in the area of the head-neck. HNO 41: 526-531. [Crossref]

2. Pellitteri PK, Rinaldo A, Myssiorek D, Gary Jackson C, Bradley PJ, et al. (2004) Paragangliomas of the head and neck. Oral Oncol 40: 563-575. [Crossref]

3. Wieneke JA, Smith A (2009) Paraganglioma: carotid body tumor. Head Neck Pathol 3: 303-306. [Crossref]

4. Boscarino G, Parente E, Minelli F, Ferrante A, Snider F (2014) An evaluation on management of carotid body tumour (CBT). A twelve years experience. G Chir 35: 47-51. [Crossref]

5. Batsakis J (1976) Tumors of the head and neck. Clinical and pathological considerations. (2nd edn), Baltimore: Williams and Wilkins, pp: 280-288.

6. Kruger AJ, Walker PJ, Foster WJ, Jenkins JS, Boyne NS, et al. (2010) Important observations made managing carotid body tumors during a 25 -year experience. $J$ Vasc Surg 52: 1518-1523. [Crossref]

7. van den Berg R (2005) Imaging and management of head and neck paragangliomas. Eur Radiol 15: 1310-1318. [Crossref]

8. Pacheco-Ojeda L (2001) Malignant carotid body tumors: report of three cases. Ann Otol Rhinol Laryngol 110: 36-40. [Crossref]

9. Inci S, Bertan V (2000) Catecholamine-secreting carotid body tumor and intracrania aneurysm: coincidence? Surg Neurol 53: 488-492. [Crossref]

10. Ikejiri K, Muramori K, Takeo S, Furuyama M, Yoshida K, et al. (1996) Functional carotid body tumor: report of a case and a review of the literature. Surgery 119: 222225. [Crossref]

11. Luna-Ortiz K, Rascon-Ortiz M, Villavicencio-Valencia V, Granados-Garcia M, Herrera-Gomez A (2005) Carotid body tumors: review of a 20-year experience. Oral Oncol 41: 56-61. [Crossref]
12. Hu K, Persky MS (2016) Treatment of Head and Neck Paragangliomas. Cancer Control 23: 228-241. [Crossref]

13. Ma D, Liu M, Yang H, Ma X, Zhang C (2010) Diagnosis and surgical treatment of carotid body tumor: A report of 18 cases. J Cardiovasc Dis Res 1: 122-124. [Crossref]

14. Lazaridis N, Antoniades K (2003) Double mandibular osteotomy with coronoidectomy for tumours in the parapharyngeal space. Br J Oral Maxillofac Surg 41: 142-146. [Crossref]

15. Lazaridis N, Antoniades K (2008) Condylotomy or vertical subsigmoid osteotomy with a mandibulotomy anterior to the mental foramen for improved access to the parapharyngeal space tumors. J Oral Maxillofac Surg 66: 597-606. [Crossref]

16. Gonzalez C, Rocher A, Zapata P (2003) Arterial chemoreceptors: Cellular and molecular mechanisms in the adaptative and homeostatic function of the carotid body Rev Neurol 36: 239-254.

17. Shamblin WR, ReMine WH, Sheps SG, Harrison EG Jr (1971) Carotid body tumor (chemodectoma). Clinicopathologic analysis of ninety cases. Am J Surg 122: 732-739. [Crossref]

18. Jones HG, Stoneham MD (2006) Continuous cervical plexus block for carotid body tumour excision in a patient with Eisenmenger's syndrome. Anaesthesia 61: 12141218. [Crossref]

19. Sajid MS, Hamilton G, Baker DM; Joint Vascular Research Group (2007) A multicenter review of carotid body tumour management. Eur J Vasc Endovasc Surg 34: 127-130. [Crossref]

20. Makeieff M, Raingeard I, Alric P, Bonafe A, Guerrier B, et al. (2008) Surgical management of carotid body tumors. Ann Surg Oncol 15: 2180-2186. [Crossref]

21. Dardik A, Eisele DW, Williams GM, Perler BA (2002) A contemporary assessment of carotid body tumor surgery. Vasc Endovascular Surg 36: 277-283. [Crossref]

22. White JB, Link MJ, Cloft HJ (2008) Endovascular embolization of paragangliomas: A safe adjuvant to treatment. $J$ Vasc Interv Neurol 1: 37-41. [Crossref]

23. Smith RF, Shetty PC, Reddy DJ (1988) Surgical treatment of carotid paragangliomas presenting unusual technical difficulties. The value of preoperative embolization. $J$ Vasc Surg 1988; 7:631-7. [Crossref]

24. Power AH, Bower TC, Kasperbauer J, Link MJ, Oderich G, et al. (2012) Impact of preoperative embolization on outcomes of carotid body tumor resections. J Vasc Surg 56: 979-989. [Crossref]

25. Sen I, Stephen E, Malepathi K, Agarwal S, Shyamkumar NK, et al. (2013) Neurological complications in carotid body tumors: a 6-year single-center experience. $J$ Vasc Surg 57: 64S-8S. [Crossref]

26. Schlieve T, Carlson ER, Freeman M, Buckley R, Arnold J (2017) The Double Mandibular Osteotomy for Vascular and Tumor Surgery of the Parapharyngeal Space. J Oral Maxillofac Surg 75: 1046-1061. [Crossref]

27. Basaran B, Polat B, Unsaler M, Ulusan M, Aslan I, et al. (2014) Parapharyngeal space tumours: The efficiency of a transcervical approach without mandibulotomy through review of 44 cases. Acta Otorhinolaryngol Ital 34: 310. [Crossref]

28. Kolokythas A, Fernandez RP, Ord R (2007) A Non-Lip-Splitting Double Mandibular Osteotomy Technique Applied for Resection of Tumors in the Parapharyngeal and Pterygomandibular Spaces. J Oral Maxillofac Surg 65: 566-569. [Crossref]

29. Kolokythas A, Eisele DW, El-Sayed I, Schmidt BL (2009) Mandibular osteotomies for access to select parapharyngeal space neoplasms. Head Neck 31: 102-110. [Crossref]

Copyright: (C2017 Paraskevopoulos K. This is an open-access article distributed under the terms of the Creative Commons Attribution License, which permits unrestricted use, distribution, and reproduction in any medium, provided the original author and source are credited. 